\title{
Assessment of clinical manifestations related to palmoplantar keratoderma and its impact on quality of life of cases
}

\author{
Bhaskara Narayana \\ Professor, Dept. of Dermatology, Venerealogy and Leprosy, MNR Medical College \& Hospital, Sangareddy, Telangana, India
}

*Corresponding Author:

Email: kbn.dermatology1955@gmail.com

\begin{abstract}
Introduction: Palmoplantar keratodermas (PPKs) is heterogeneous entity of cutaneous disorders, with hyperkeratinisation of stratum corneum over palm and soles. PPKs can be hereditary or acquired. Acquired PPK occurs in later years due to continuous or constant exposure to allergens, irritants and exposure to trauma.

Aim: This study undertaken to assess the clinical manifestations related to Palmoplantar keratoderma cases and its impact on quality of life of cases.

Materials and Methods: A total of 106 patients with chief complaints of Palmoplantar keratoderma attending outpatient department of DVL were included. Detailed clinical history regarding diseases status was collected. The Patients feedback was taken as impact scores i.e. 3 (Very good), 2 (Good), 1 (Moderate), 0 (Poor). QOL was measured by grading system based on the patient's feedback.

Results: Majority cases were between $2^{\text {nd }}$ to $4^{\text {th }}$ decades $(65 \%)$. Housewives $(30.1 \%)$ and daily wage labourers $(24.5 \%)$ were more commonly affected by acquired PPK. Psoriasis (52.8\%) followed by Eczema (15.09\%), Pityriasis rubra pilaris (8.4\%) and Erythroderma dermatitis (5.6\%) are common symptoms associated with PPK. There is a notable impact of PPK on quality of life of patients in $57.4 \%$ cases.

Conclusion: Acquired PPK is always misdiagnosed because it is nonhereditary. House wives and daily wage workers are commonly affected due to constant exposure to detergents, chemicals and various forms of trauma. Palmoplantar keratodermas has remarkable impact on quality of life of patients.
\end{abstract}

Keywords: Palmoplantar keratoderma (PPK), Psoriasis, Occupation, Prevalence, Quality of life (QOL).

\section{Introduction}

Palmoplantar keratoderma (PPK) is a disorder of keratinization, characterized by a diffuse or focal thickening of the stratum corneum over palmoplantar region. ${ }^{1}$ Diffuse, focal and punctuate are type of PPKs, division is based on mode of inheritance, morphology, comorbidities with other symptoms, erythematous borders, hyperhidrosis and area of epidermal involvement over palm and soles. ${ }^{2}$ Keratodermas can be both acquired and hereditary.

Acquired PPK is nonhereditary and non-frictional hyperkeratosis which occur later in life, with a possible etiology like infections, reactive and inflammatory dermatoses, and other systemic complications. ${ }^{3}$ It appears over palms and soles involving more than 50\% of the acral areas. Acquired PPK occurs due to multiple causes i.e. psoriasis, human papillomavirus, eczema, paraneoplastic keratoderma, calluses, dermatophytosis etc. $^{4}$

With the wide etiologic factors involvement and minimal availability of clinical and epidemiologic literature, the present study designed to assess the clinical manifestations of related to Palmoplantar keratoderma and its impact on quality of life of cases.

\section{Materials and Methods}

The present descriptive study was conducted in Department of DVL, MNR Medical College and Hospital, Sangareddy during April 2016 to March 2018.
A total 106 cases attending outpatient department of DVL with chief complaints of Palmoplantar keratoderma were recruited for the study. Informed consent was obtained from all the patients and study protocol was approved by institutional ethics committee. Patients of both sexes with chief complaints of Palmoplantar keratoderma (acquired \& inherited), cases between 1-50 years of age and with positive family history were included in the study. Patients who were not willing to participate, with $>50$ years age and other dermatological disorders were excluded from the study.

A detailed clinical history of the patients was collected i.e. Disease progression, Palm and sole involvement, keratotic surface discoloration, recurrent skin infections, scaling of skin, feature of scales, fissures and its bleeding from keratotic surface, burning sensation, other issues of pigmentation, photosensitivity and pain. Past treatment profile and history of palmoplantar keratoderma was noted.

Quality of life (QOL), of cases were assessed by a score based patients enquiry on pain, itchiness of skin, difficulties at working places, during sports, during social activities, during interaction with friends and relatives, sexual difficulties with partner and related to treatment methods treatment. The Patients feedback was taken as impact scores i.e. 3 (Very good), 2 (Good), 1 (Moderate), 0 (Poor). QOL was measured by grading system based on the patient's feedback. Data was extracted and 
analysed to calculate the percentages by using Microsoft excel sheet.

\section{Results}

A total 106 cases with palmoplantar keratoderma were considered between age group $1^{\text {st }}$ to $7^{\text {th }}$ decades
(Fig. 1). Among 7800 cases attended outpatient wing of Department of DVL, MNR Medical College and Hospital during study period, 106 patients $(0.013 \%)$ were diagnosed with acquired palmoplantar keratoderma and recruited for the study. Among the participants majority were in between age group $2^{\text {nd }}$ to $6^{\text {th }}$ decade (Fig. 1).

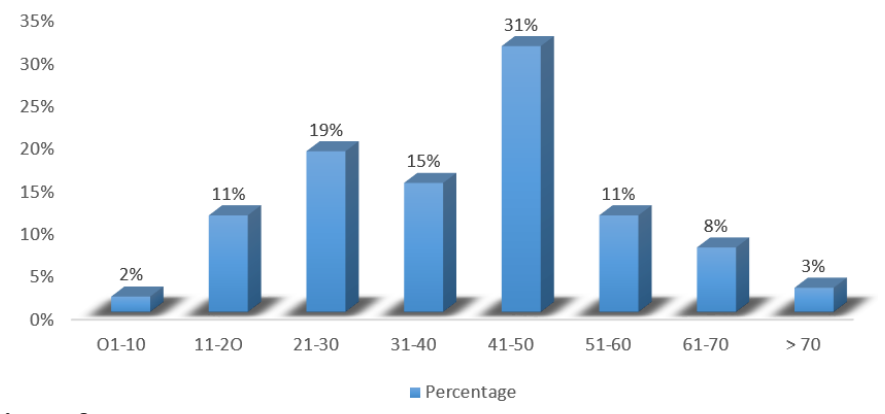

Fig. 1: Age wise distribution of cases

Table 1: Distribution of acquired cases based on occupation.

\begin{tabular}{|l|c|c|}
\hline \multirow{2}{*}{\multicolumn{1}{c|}{ Occupation }} & \multicolumn{2}{c|}{ Acquired PPK } \\
\cline { 2 - 3 } & Number & Percentage \\
\hline Unemployed & 10 & $9.4 \%$ \\
\hline Daily wage Labourer & 26 & $24.5 \%$ \\
\hline Student & 12 & $11.3 \%$ \\
\hline Housewives & 32 & $30.1 \%$ \\
\hline Garage workers & 12 & $11.3 \%$ \\
\hline Fisherman & 09 & $8.4 \%$ \\
\hline Office work/printing press & 05 & $4.7 \%$ \\
\hline
\end{tabular}

Housewives $(30.1 \%)$ and daily wage labourers $(24.5 \%)$ contributed more in acquired PPK, followed by Students (11.3\%), garage workers (11.3\%), Unemployed (9.4\%), fisherman (8.4\%) and office workers (4.7\%) (Table 1). Focal type (54.7\%) is most common clinical pattern type in acquired PPK patients followed by diffuse type (45.2\%) (Table 2).

Table 2: Clinical pattern in acquired PPK

\begin{tabular}{|l|c|c|c|}
\hline & Gender & Number & Percentage \\
\hline \multirow{2}{*}{ Diffuse $(\mathrm{n}=48)$} & Male & 20 & $18.8 \%$ \\
\cline { 2 - 4 } & Female & 28 & $26.4 \%$ \\
\hline \multirow{2}{*}{ Focal $(\mathrm{n}=58)$} & Male & 38 & $35.8 \%$ \\
\cline { 2 - 4 } & Female & 20 & $18.8 \%$ \\
\hline Punctate $(\mathrm{n}=0)$ & Male & - & - \\
\cline { 2 - 4 } & Female & - & - \\
\hline
\end{tabular}

Table 3: Etiological characteristics of acquired PPK

\begin{tabular}{|l|c|c|}
\hline \multicolumn{1}{|c|}{ Disease } & Total no cases & Percentage \\
\hline Eczema & 16 & $15.09 \%$ \\
\hline Pitted keratolysis & 04 & $3.7 \%$ \\
\hline Psoriasis & 56 & $52.8 \%$ \\
\hline Lichen planus & 03 & $2.8 \%$ \\
\hline Pityriasis rubra pilaris & 09 & $8.4 \%$ \\
\hline Erythroderma dermatitis & 06 & $5.6 \%$ \\
\hline Atopic dermatitis & 03 & $2.8 \%$ \\
\hline Crusted scabies & 05 & $4.7 \%$ \\
\hline Mycosis fungoides & 02 & $1.9 \%$ \\
\hline Reiters syndrome & 02 & $1.9 \%$ \\
\hline
\end{tabular}


Psoriasis $(52.8 \%)$ is the commonest clinical manifestation associated with PPK followed by eczema

(15.09\%) (Table 3). A total $67.9 \%$ cases had extreme and remarkable effect on the life due to PPK.

Table 4: Assessment of quality of life by grading system in acquired PPK patients

\begin{tabular}{|l|c|c|}
\hline \multirow{2}{*}{ Effect on life } & \multicolumn{2}{|c|}{ Total no of cases } \\
\cline { 2 - 3 } & Number & Percentage \\
\hline No change & 02 & $1.8 \%$ \\
\hline Mild change & 08 & $7.5 \%$ \\
\hline Moderate change & 24 & $22.6 \%$ \\
\hline Remarkable change & 58 & $54.7 \%$ \\
\hline Extreme change & 14 & $13.2 \%$ \\
\hline
\end{tabular}

\section{Discussion}

Palmoplantar keratodermas (PPK) is a thickening of skin of the palm and sole due to hyperkeratosis. ${ }^{5,6} \mathrm{PPK}$ is referred as heterogeneous group of disorders and is divided as acquired or hereditary. ${ }^{7,8}$ Clinically, acquired PPK have various epidermal pattern of involvement, diffuse, focal and punctuate types. Diffuse PPK refers to uniform involvement of palmoplantar surface, focal PPK refers over pressure points which may be striate or oval and punctuate PPK having multiple scattered, round lesions of tiny keratotic papules on palm and sole. ${ }^{8,9}$ This study was designed to assess the clinical profile, its associated symptoms in patients with palmoplantar keratodermas.

Several studies noted that the cases between the ages $17-40$ years $(42.7 \%)(10), 40-59$ years $(36.2 \%)^{11}$ and $41-50$ years $(26 \%){ }^{12} 21-30$ years $^{13}$ were prone to PPK. In this study majority cases were between 21-50 years (65\%) which is correlating with the above studies and age of onset was noted during second decade.

PPK was most common in housewives (30.2\%), labourers (26.2\%) and students (25.2\%) due to their high exposure to chemicals, friction, detergents and water while their daily activities. ${ }^{10}$ Kodali et al., stated that farmers $(53 \%)$ and housewives $(20 \%)$ were commonly affected, ${ }^{12}$ Chopra et al., stated that housewives $(18.69 \%)$ and manual workers $(48.16 \%)$ are commonly affected, with PPK. ${ }^{14}$ Study by Mahajan et al., reported that manual labourer (48.16\%), students (33.1\%) and housewives (18.69\%) affected by PPK. ${ }^{15}$ Another study by Murthy SC et al., reported that farmers and manual labourers are commonly affected by PPK. ${ }^{16}$ In present study, housewives (30.1\%) affected more common, followed by daily wage labourers (24.5\%), garage workers $(11.3 \%)$ and students $(11.3 \%)$.

In present study psoriasis $(52.8 \%)$ is the most common symptom associated with PPK which is correlating with the findings of Chopra et al., and Murthy SC et al..$^{14,16}$ In this study PPK is also associated with Eczema in $15.09 \%$ cases, with Pityriasis rubra pilaris in $8.4 \%$ cases, with Erythroderma dermatitis in 5.6\%, with Pitted keratolysis in $3.7 \%$ cases. In this study impact of PPK on quality of life of patients was extreme and remarkable in $67.9 \%$ cases and is moderate on $22.6 \%$ cases (Table 4 ).

\section{Conclusion}

Acquired PPK is a nonhereditary and non-frictional hyperkeratosis of palms and soles which inculpate half of the acral area and more. The results concluded that majority cases with acquired PPK were housewives and daily wage labourers. Psoriasis followed by Eczema, Pityriasis rubra pilaris and Erythroderma dermatitis are common symptoms associated with PPK. Observed notable impact of PPK on quality of life of patients in $57.4 \%$ cases. Clinical evaluation of acquired PPK is always need attention of clinician to find out the exact cause. This study focused on clinical profile of acquired PPK, but detailed evaluation is required on all subtypes of PPKs with more sample size.

Funding: No funding sources.

Conflict of interest: None declared.

\section{References}

1. Judge MR, McLean WHI, Munro CS. Disorders of keratinization. In: Burns T, Breathnac S, Cox N, Griffiths C. Rook's Textbook of Dermatology. 7th ed. Blackwell Publishing Company 2004;34:1-111.

2. Stevens HP, Leigh IM, Fitzpatrick TB, Freeberg IM, Eisen AZ, Wolff K, et al. Keratoderma of palms and soles. In: Dermatology in General Medicine. 5th edn. New York: McGraw-Hill 1999;603-13.

3. Patel S, Zirwas M, English JC. Acquired Palmoplantar Keratoderma. Am J Clin Dermatol 2007;8:1-11.

4. Venkatesan A, Aravamudhan R, Perumal SK, Kannan R, Thirunavukkarasu V, Shukla S. Palmoplantar PsoriasisAhead in the Race-A Prospective Study from a Tertiary Health Care Centre in South India. J Clin Diagn Res 2015;9:1-3.

5. Kang BS, Lee JD, Cho SH. A Clinicopathological Study of Palmoplantar Dermatoses. Korean J Dermatol 2006;44:714 20.

6. Itin PH, Fistrol SK. Palmoplantar keratodermas. Clin Dermatol 2005;23:15-22.

7. Freedberg IM, Eisen AK, Wolff K, et al. Fitzpatrick's dermatology in general medicine. 6th edn. New York: McGraw-Hill, 2003.

8. Champion RH, Burton JL, Burns DA, et al. Rook, Wilkinson, Ebling textbook of dermatology. 7th ed. Malden (MA): Blackwell Science Ltd, 2004;34:79-107.

9. Bolognia JL, Jorizzo JL, Rapini RP. Dermatology. New York: Mosby, 2003:809-10.

10. Pragya A. Nair, Nilofar G. Diwan, Rochit Singhal, and Rita V. Vora. A Prospective Study of Clinical Profile in Patients of Palmoplantar Dermatoses. Indian Dermatol Online J 2017;8(5):331-35.

11. Kang BS, Lee JD, Cho SH. A Clinicopathological Study of Palmoplantar Dermatoses. Korean J Dermatol 2006;44:714 20.

12. Kodali S. A Clinico-Histopathological Study of Acquired Palmoplantar Keratoderma in a Rural-Based Tertiary Hospital. J Evolution Med Dent Sci 2014;30:8500-5.

13. Amrita A Hongal, Nadiga Rajashekhar, Somashekar Gejje. Palmoplantar Dermatoses- A Clinical Study of 300 Cases. $J$ Clin Diagnostic Res 2016;10(8):4-7. 
14. Chopra A, Maninder, Gill SS. Hyperkeratosis of palms and soles: Clinical study. Indian J Dermatol Venereol Leprol 1997;63:85-8.

15. Mahajan VK, Thakur NS, Sharma NL. Papillon-Lefevre syndrome. Indian Pediatr 2003;40:1197-200.

16. Sambasiviah Chidambara Murthy.MD,Tanjore Y. Raghu. MD, Tamraparini Suresh. M.D Study of palmoplantar keratodermas in South India. Int J Dermatol 2008;47(7):76264.

How to cite this article: Narayana B. Assessment of clinical manifestations related to palmoplantar keratoderma and its impact on quality of life of cases. Indian J Clin Exp Dermatol 2018;4(4):274-77. 